\title{
An overview of the microclimate conditions inside healing chambers
}

\author{
Ionel Lucian Dumitrescu ${ }^{1,2}$, Adrian-Gabriel Ghiaus, ${ }^{1, *}$ \\ ${ }^{1}$ Technical University of Civil Engineering, 020396 Bucharest, Romania \\ ${ }^{2}$ ICDIMPH-HORTING Institute, 042159 Bucharest; Romania
}

\begin{abstract}
In the civil and industrial construction engineering, the comfort of occupants is ensured by achieving appropriate microclimate conditions. The human physical comfort (thermal, visual, acoustic) is achieved when the person from an enclosure is in a state of equilibrium and is able to perform tasks with maximum possible efficiency and without any kind of stress. Similarly, in the case of crops grown inside protected spaces, for plants, just as in the case of human being, specific microclimate conditions need to be ensured for their optimum development during the vegetation period. Plant development is a result of its own genetic features, but this is influenced by microclimate conditions inside of the greenhouses. Even more, in the case of healing and acclimatization rooms for grafted vegetables, the specific microclimate conditions must be strictly monitored. Technologically, it is recommended an optimum indoor temperature between $23^{\circ} \mathrm{C}$ and $25^{\circ} \mathrm{C}$, with a maximum value that must not exceed $28^{\circ} \mathrm{C}$, under conditions of relative humidity around $85 \%-95 \%$. Other two important aspects are the $\mathrm{CO}_{2}$ concentration and the level of solar radiation. The value of the $\mathrm{CO}_{2}$ concentration is an indicator of the healing process. For the grafting process, it is useful to know the time of the connection of the donor and receiver. Led by the the light levels, the photosynthetic activity of the grafted seedlings in the healing period, lead to a decreasing of $\mathrm{CO}_{2}$ concentration. This means that the two parts of the planting material are jointed, healed. So, the farmers can manipulate the environment in the healing rooms. This paper presents an overview of the scientific and technical issues that have to be achieved in order to reach suitable control and management of microclimate conditions in healing rooms for grafted vegetables.
\end{abstract}

\section{Introduction}

The use of grafted plants on resistant genotypes is now widely widespread in the world. Vegetable grafting is a horticultural technique by which two plants are joined together in the seedling stage to create a plant with improved characteristic to resistance to soil diseases and/or to soil nematode, which corresponds to the farmers' requirements in terms of quality and productivity.

Practically, the top of a plant (scion) with good fruit quality and good yield is attached to the rootstock of a tolerant or disease resistant plant, nematodes or other extreme conditions such as soil salinity, drought, excessive humidity, etc. [1]. Grafting not only can increase the disease-resistant ability but also can promote the production quality for vegetable crops. Since both rootstock and scion are cut for grafting, they need to reconstruct their vascular bundles in the course of callusing process. Therefore, vegetable grafting must be carried out in monitored and controlled environment.

A successful grafting of vegetables requires high relative humidity $(\mathrm{RH})$ and optimal temperature for one week following grafting to reduce transpiration of the scion until rootstock and scion vascular tissue are healed together and water transport is restored. Generally in the healing room, according to the seedlings cultivar, the adjustable temperature ranges from $15^{\circ} \mathrm{C}$ to $27^{\circ} \mathrm{C}$ with a control precision of $\pm 0.5^{\circ} \mathrm{C}$, relative humidity (RH) can be controlled within the range of $60 \%$ to $95 \%$ with control precision of $\pm 3 \%$ and the light adjustable range is from 0 to $50001 \mathrm{x}$ [2]. According to Rivard and Louws [3] presented in Figure 1, the whole process from seeding to grafting, healing and transplanting in the field lasts five weeks. The complete vascular connection establishment takes approximately five to eight days, during which the scion is unable to uptake water through the rootstock. Therefore, reducing scion transpiration is crucial for the grafting survival [4]. In order to reduce scion water loss to the surrounding environment, the air relative humidity (RH) should be high, ranging from $85 \%$ to $100 \%$ [5] However, specific timing of rootstock and scion seeding as well as the total propagation time will vary based on the greenhouse environment and light intensity within a given propagation area.

* Corresponding author: adrian.ghiaus@utcb.ro 


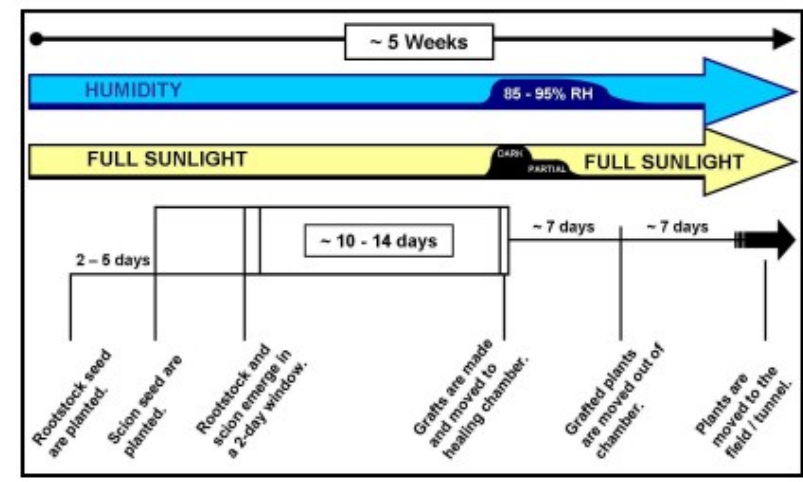

Fig. 1. Timeline for grafting [3]

Generally, healing and acclimatization of the grafted plants are done in particular chambers inside a greenhouse. They involve healing of the cut surface and hardening for field or greenhouse survival [6]. The healing room can provide a suitable artificial environment for newly grafted vegetable seedlings. The environment can be controlled based on the healing requirements of grafted seedlings through automatic control of artificial climate, including relative humidity, temperature, light, wind speed, and other environmental factors. This can be a challenging task, requiring frequent monitoring and continuous adjustment of the environment conditions in the grafting chamber. Out of the grafting season, the grafting chamber can be used as acclimatization chambers for non-grafted seedlings of other crops.

\section{Overview on healing and acclimation chamber for grafted seedlings}

The first prototypes of this type of chambers were developed in England and in the Netherlands in the early 1960s [7]. These chambers are mainly used for the production of seedlings, but they could also be used to grow plants up to the maturity stage only for valuable crops or for growing plants in areas with extreme atmospheric conditions due to due to high operating costs. Also, this type of premises is used successfully in obtaining grafted seedlings when the internal microclimate conditions must be very strict.

Advanced technologies on controlling microclimate factors and the equipment that can modify these factors according to crop requirements, can completely transform a shelter into a completely independent enclosure by outside weather conditions.

\subsection{Healing chambers with manual control of microclimate factors}

In 2006 at North Carolina State University (NCSU) Department of Plant Pathology, Rivard and collaborators [8] conducted an experiment to demonstrate that the graft process can be quite affordable financial speaking, for small, family farms. In grafting process, immediately after the joining of the two plants, it is necessary to restore the graft and graft port as the graft does not yet have a biological root connection and cannot be fed with water and nutrients. Therefore, the calming chamber has to reduce the stress that might occur due to lack of water to which the graft is subjected. The best way to do this is to increase the humidity inside the premises, decrease the intensity of light radiation and reduce the temperature. In this way, the seedling evapotranspiration process is diminished. Thus, a calming chamber must ensure during the healing period high humidity, low light intensity and moderate temperature. In addition, these indicators, humidity, luminous intensity and temperature must be as constant as possible. The humidity should be about $80 \%$ to $95 \%$, the temperature between $21^{\circ} \mathrm{C}$ and $26^{\circ} \mathrm{C}$ and no solar radiation (it is preferable to use artificial light in the first 5-7 days after grafting).

Figure 2 shows the calming chamber built by NCSU researchers [8], an extremely simple and cheap construction.

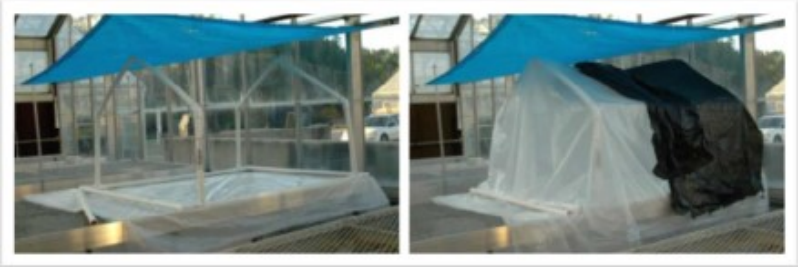

Fig. 2. NCSU healing chamber [8]

The chamber is placed inside a greenhouse on a working table under a foil which can assure shade in the room. The room was built on a foil with which, by lifting the edges, a small reservoir of water will be formed, which will be the water source to maintain humidity. The skeleton was built of 1 inch PVC pipes. The whole structure was wrapped with plastic foil, and the access inside being very easy, and for the shading, were used black plastic bags which were cut longitudinally.

In general, the materials from which these cheap healing chambers are built, are chosen from the local resources such as: bamboo, PVC pipes, bricks, nylon nets, wood boards, black and transparent polyethylene film, silver/black/green shades, plastic clamps, ropes, wire or nails.

In 2016, Miles and collaborators from Washington State University [9] proposes a new model of healing chambers showed in Figure 3. He pointed out that the room size is very important in order to control the humidity inside, because in a higher room it will be difficult to maintain a constant level of high humidity. In addition, the length and width must ensure a low variation of humidity inside when it is closed or opened. To control the humidity inside this premises, a spray hose or a spray-type manual container can be used to moisten the entire space as well as the seedling trays before being inserted into the chamber. Plastic sheeting holds in water to maintain high humidity and shade cloth limits light to reduce photosynthesis and water loss from the scion. Immediately after the seedlings are introduced inside, fully cover the chamber and seal it as well as possible. High moisture variations in the critical 5-day period can cause inappropriate seedlings, or even survival rates may drop dramatically. 


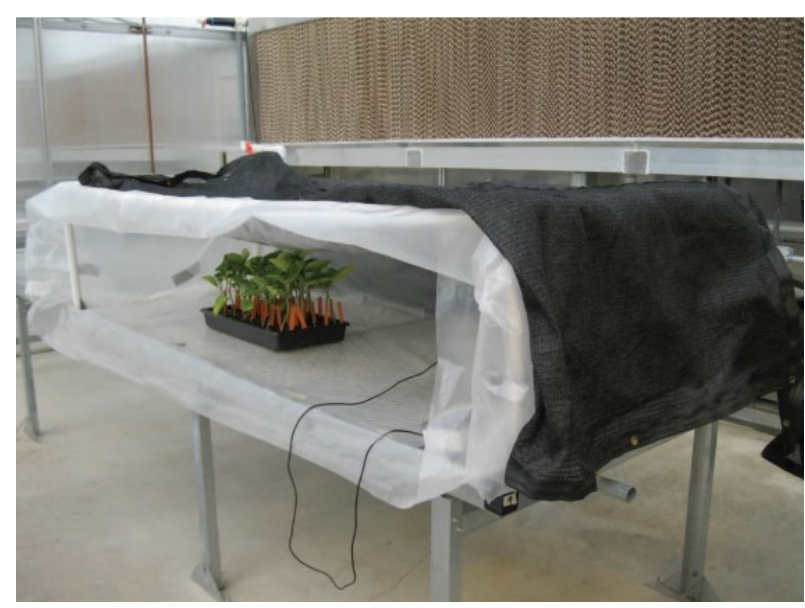

Fig. 3. Healing chamber constructed on a bench in a greenhouse [9]

\subsection{Automated healing chambers}

A very important element in obtaining the quality and quantity required of grafted vegetables are the microclimate factors in the incites where the seedlings are grown. The stages to obtain grafted seedlings are relatively short and the fluctuations in environmental factors may have dramatic effects on the seedlings production. For this reason, the use of healing rooms with automated control of microclimate factors for seedlings production is a very useful method. The advantages of using an artificial environment are mainly the predictability of the production indicators and the standardization of the seedlings quality as a result of the constancy of the microclimate conditions in the calming chambers.

In the proper scientific world, there are many concerns about the development of these automatic healing facilities. In these way, in 2011 Mun and collaborators [10] used a healing chamber with three boxes, developed by Chiba University, Japan, to test the $\mathrm{CO}_{2}$ exchange rate in the healing chambers during the healing and acclimatization of vegetable seedling.

The $\mathrm{CO}_{2}$ exchange rate gives accurate information on the intensity of the photosynthesis process of the seedlings. An intense photosynthesis process with decreases in $\mathrm{CO}_{2}$ concentration shows that the connection between the scion and rootstock has been achieved, so the grafted plants are healed. In Figure 4 is schematically presented this healing room used to continuously measure the $\mathrm{CO} 2$ exchange rates in grafted cucumber plants, developed at Chiba University, Japan [9]. The environment is controlled by a humidifier, heater, and cooler attached to the data logger and controller. Different light intensities can be applied above the healing box. The air in each box could be sampled, dehumidified and measured at the defaults intervals. The abbreviations used are: thermocouple (TC), relative humidity $(\mathrm{RH})$, solenoid valve (SV), and air pump (P).

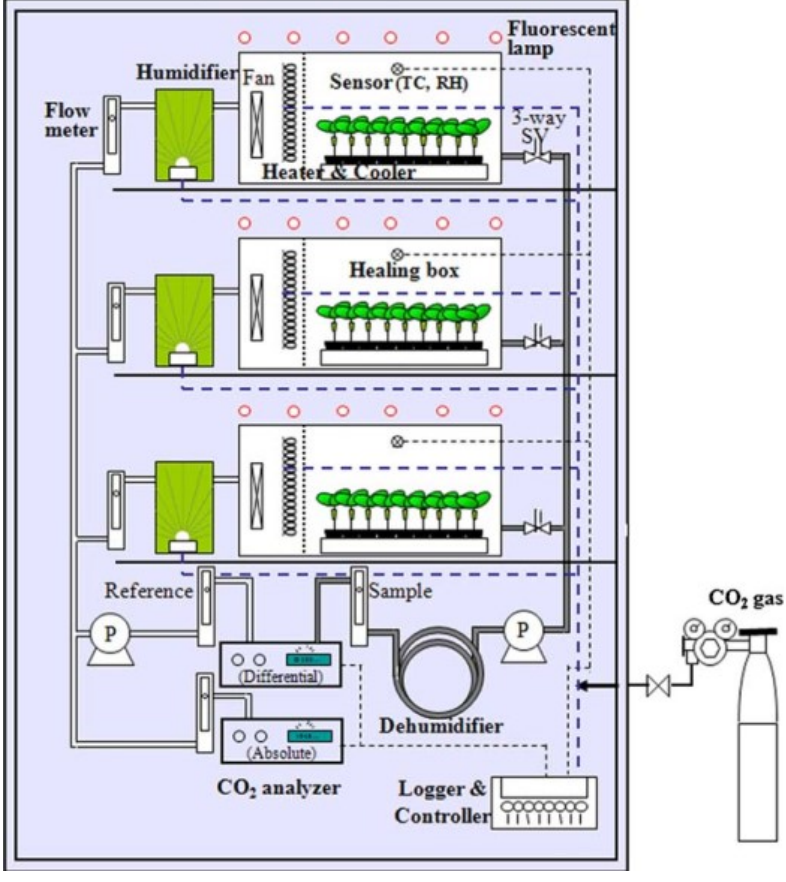

Fig. 4. Diagram of the semi-open multi-chamber [9]

Figure 5 shows the seedlings placed in the healing boxes where are gradually exposed to different PPFD (Photosynthetic Photon Flux Density) and different RH (Relative Humidity) conditions during healing and acclimatization [9].

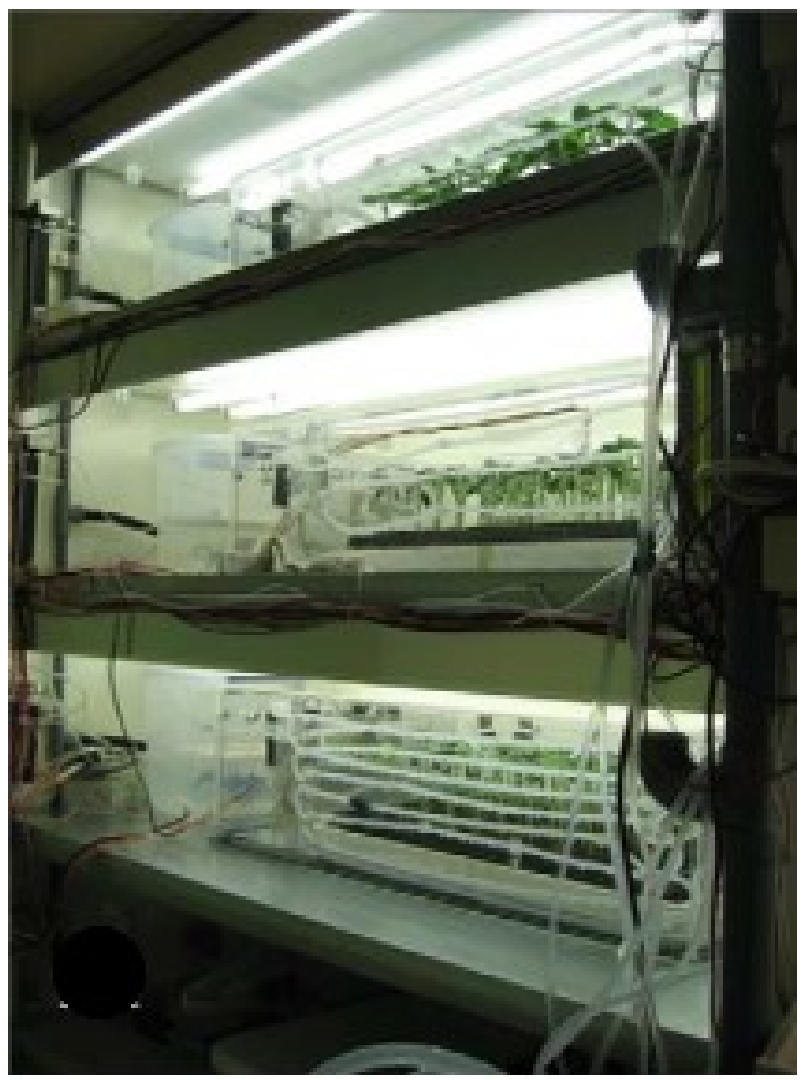

Fig. 5. View of the system for measuring the $\mathrm{CO}_{2}$ exchange rate of grafted seedlings [9] 
An similar equipment with 10 distinct rooms was used by Van Iersel [10] from the Department of Horticulture at the University of Georgia, USA. This multi-chamber system allows the installation of multiple experimental variants with different microclimatic and / or biological parameters. The scheme of such an installation is shown in Figure 6.

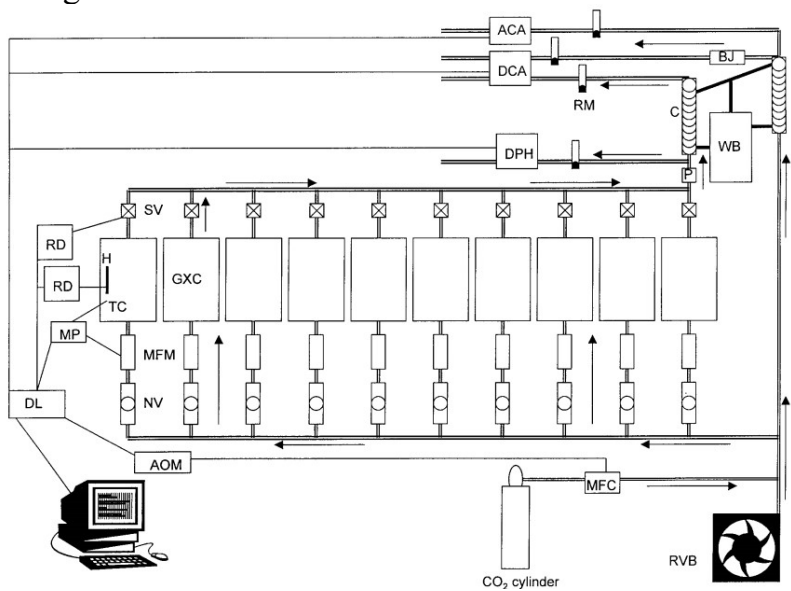

Fig. 6. Diagrammatic representation of a multiple chamber system for semi continuous $\mathrm{CO}_{2}$ exchange measurements [10]

The meaning of the abbreviations in the figure 6 are : $\mathrm{ACA}=$ absolute $\mathrm{CO} 2$ analyzer, $\mathrm{AOM}=$ analog output module, $\mathrm{BJ}=$ buffer jar/air flow regulator jar, $\mathrm{C}=$ condensor (to remove water from the air), DCA = differential $\mathrm{CO} 2$ analyzer, $\mathrm{DL}=$ datalogger, $\mathrm{DPH}=$ dew point hygrometer, $\mathrm{GXC}=$ gas exchange chamber, $\mathrm{H}=$ heater, $\mathrm{MFC}=$ mass flow controller, $\mathrm{MFM}=$ mass flow meter, $\mathrm{MP}=$ multiplexer, $\mathrm{NV}=$ needle valve, $\mathrm{P}=$ pump, $\mathrm{RM}=$ rotometer, $\mathrm{RVB}=$ rotary vane blower, $\mathrm{SV}=$ solenoid valve, $\mathrm{WB}=$ water bath, $\mathrm{RD}=$ relay driver, $\mathrm{TC}$ $=$ thermocouple.

Each healing chamber have the following size: length $0.47 \mathrm{~m}$, width $0.36 \mathrm{~m}$ and height $0.61 \mathrm{~m}$. The schematic diagram of these cambers is show in Figure 7.

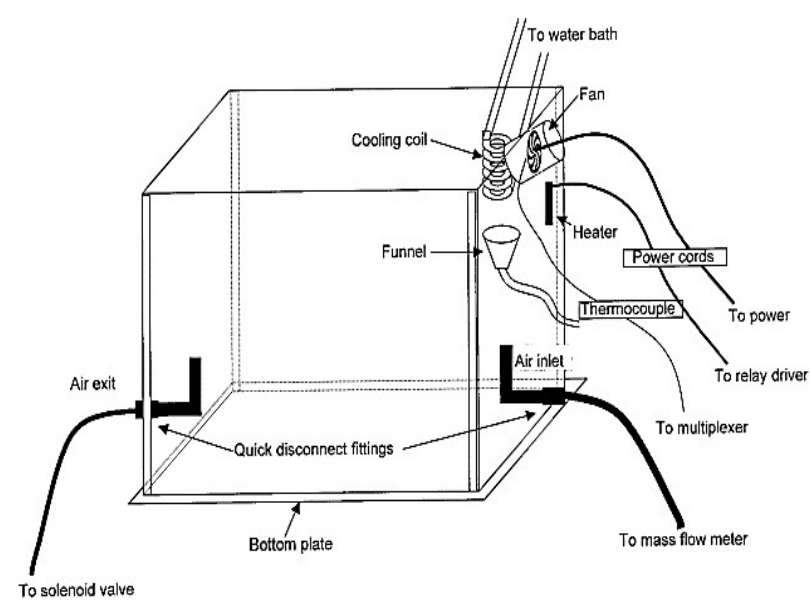

Fig. 7. Diagrammatic representation of healing chamber [10]

\subsection{Industrial healing/acclimatization chambers}

In modern commercial grafted seedlings farms, grafting process takes place in special incites where all the microclimate factors are controlled in the way to obtain high quality and a high survival rate of the seedlings. The survival rate depends on following factors: (i) method of grafting; (ii) the microclimate conditions in witch the healing is conducted; (iii) the subsequent acclimatization (hardening) process [11].

Figure 8 shows the principle of monitoring and control of microclimate factors in industrial healing or acclimatization rooms [12].

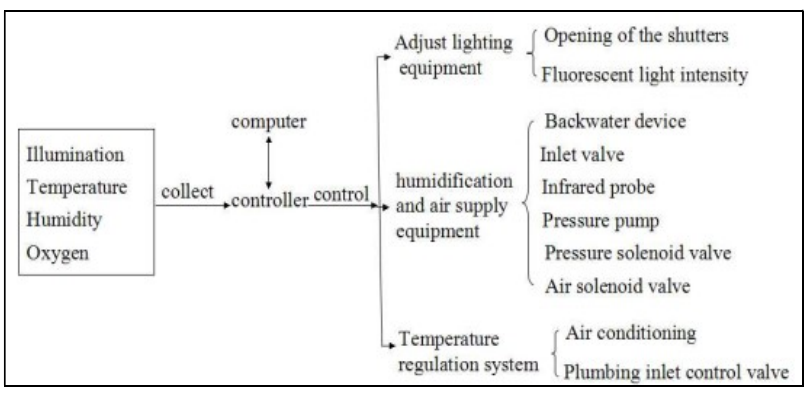

Fig. 8. Schematic diagram of environmental control system of a healing room [12]

In this regard, in 1999, Chiu and collaborators [13] developed an closed automated healing room at Lan Yang Institute of Technology in Taiwan. The room dimensions were $3.52 \times 1.8 \times 2.1 \mathrm{~m}$, where the isolating walls have a thickness of $50 \mathrm{~mm}$ and the internal height is $1.85 \mathrm{~m}$. The transfer of heat between the inside and the outside is negligible because the room is well terminal isolated. The room heating dependents on the heat generated by the lighting system, fans, and the heat generated by the breeding of the seedlings. So the temperature will increase as long as the system is operating, and decreasing during the cooling of the enclosure. An experiment has been conducted to assess the rate of temperature increase as lights and fans are operating, and so it can be determined whether additional heating or cooling equipment is needed. The results of this research have shown that such a healing / acclimatization chamber can perform the optimal microclimate conditions for the development of grafted seedlings in the post-graft period.

In 2007 Chiu and a team of collaborator [14], used the same principle to develop another healing chamber for another research. The developed room was larger than the previous one and could accommodate 12.960 seedlings during the healing period. The same microclimate control strategy was also used in this enclosure. As in the previous experiment, the developed chamber shown in Figure 9 provided optimal microclimate conditions for the healing of grafted seedlings. Temperature variations were about $1{ }^{\circ} \mathrm{C}$, relative humidity variations of about $3.6 \%$ and wind speed was less than $0.21 \mathrm{~m} / \mathrm{s}$. 


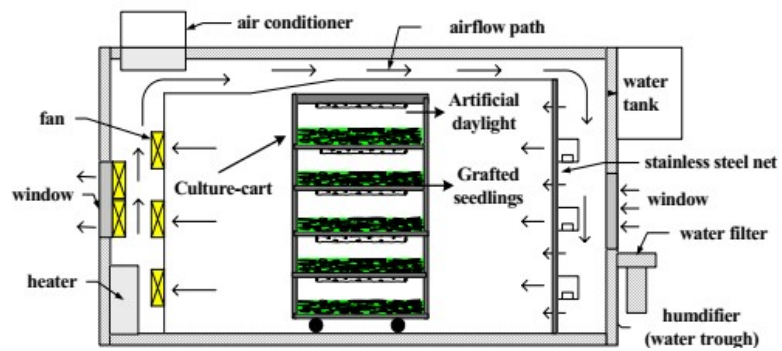

Fig. 9. Cross section of an acclimatization chamber for grafted seedlings [14]

In 2014 Dong and collaborators [12] developed an healing chamber designated to industrial production of grafted vegetable seedlings at Beijing Jing Peng International Hi-Tech Corporation. Starting from the general principle shown in Figure 7 and making the assumption that the air in the enclosure is a perfect gas, for precise and real-time control of temperature, humidity, light, $\mathrm{CO}_{2}$ concentration and other factors, it is necessary to design specific hardware and software applications.

Chinese researchers have proposed to develop a healing room where the temperature can be adjusted between $15^{\circ} \mathrm{C}$ and $30^{\circ} \mathrm{C}$ with an accuracy of $\pm 0.5^{\circ} \mathrm{C}$, the relative humidity can be vary within $60 \%$ and $90 \%$ with an adjustment accuracy of $\pm 3 \%$ and a light intensity which can be adjusted between 0 and 5000 lx. These chamber has the following structure: an intelligent environment control system (IECS), a humidification system, fertilization equipment, ventilation equipment, $\mathrm{CO}_{2}$ concentration control equipment, temperature and light control systems. The intelligent environment control system can gradually change the environmental factors (temperature, humidity, and light intensity) in the healing room in the way to to achieve the best healing environment conditions for grafted seedlings. An image from the inside of this healing room, ready for experimentation, with seedlings trays on the shelves, is shown in Figure 10.

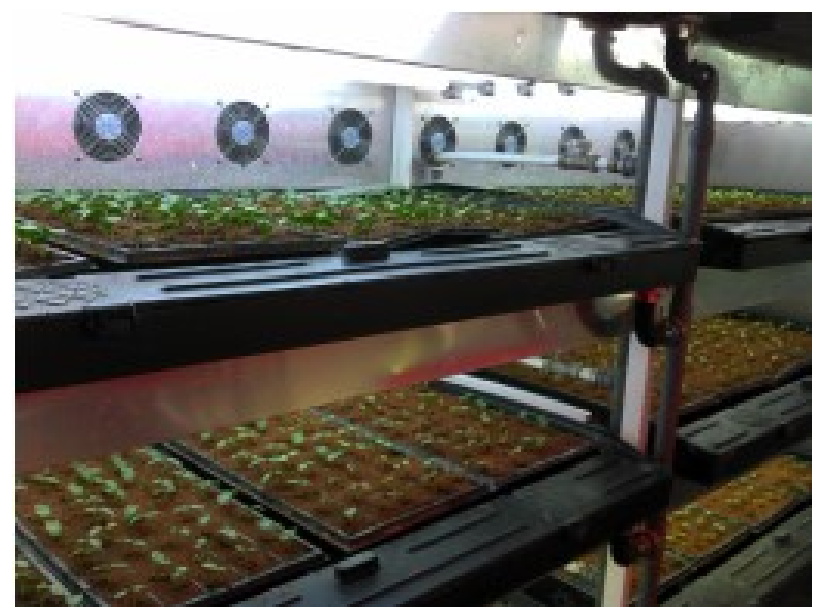

Fig. 10. Healing chamber developed in China [12]

The industrial seedlings farms use advanced technologies such as controlled environment chambers for healing and growing plants, so called 'Closed-type Plant Production System’ (CPPS). These concept can produce uniform plants, can reduce floor area by $90 \%$ as compared with regular greenhouse and can achieve $97 \%$ water use efficiency by recycling. Vegetable and grafted vegetables seedlings produced in CPPS have enhanced tolerance to environmental stress conditions.

In the Figure 11 is show a commercial plant factory room for growing lettuce, basil and other leaf greens at Mirai Co. in Japan [15]. This type of closed and fully automated farm is used for vegetable production and packaging taking place in the same room.

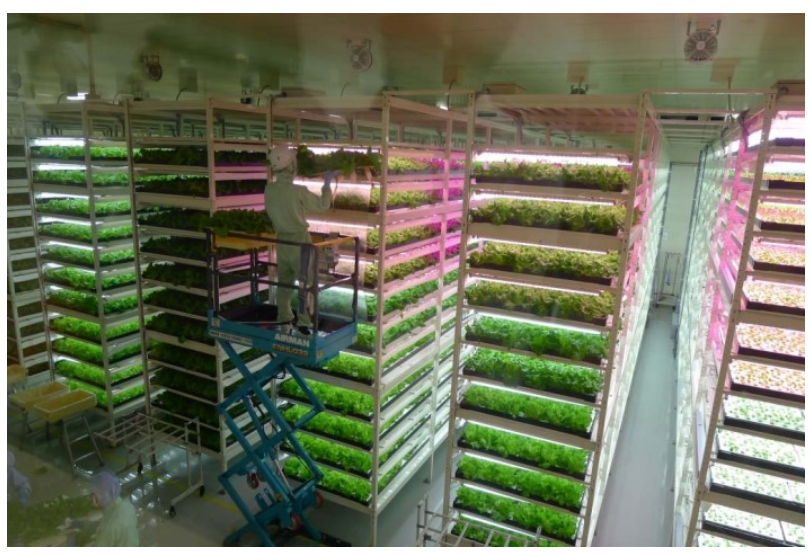

Fig. 11. A commercial plant factory room [15]

\section{Conclusions}

As a result of the use of grafted seedlings, there is a rapid increase in the demand for such high-quality seedlings by farmers. The obtaining of grafted seedlings thus becomes an important branch of horticultural production. The very important objective to be achieved during the callusing of seedlings so as to achieve the quality and quantity desired is to create a favorable microclimate in the healing rooms.

There are generally two types of healing systems: growth room specifically designed for healing and greenhousebased healing system.

Growing chambers form a uniform climate, independent of outside climatic conditions. This system is suitable for industrial production of seedlings or grafted seedlings difficult to heal. These healing rooms have, in addition of a good temperature and humidity control, supplementary artificial illumination - usually fluorescent or LED lamps - installed in multi-layer shelving units where are seated the seedlings after grafted. The stages to obtain grafted seedlings are relatively short, fluctuations in environmental factors may have dramatic effects on the quality and quantity of grafting seedlings production. For this reason, the use of artificial environments for grafting grafted seedlings is a very useful method. The advantages of using an artificial environment are mainly the predictability of the production indicators and the standardization of the seedlings quality as a result of the constancy of the microclimate conditions in the healing chambers.

Greenhouse-based healing units (inside a greenhouse or high tunnel) are widely used by small farmers. But, keeping air temperature, light intensity and humidity at 
optimum levels presents a greater challenge. To achieve adequate healing conditions in this kind of enclosure, it is essential to install: shade cloths to reduce light intensity, plastic covering to maintain high humidity, a fogging or under-bench misting system, and a heating system.

When the grafted seedlings are set in position, the relative humidity must be between $85 \%$ and $95 \%$ or even up to $95 \%$; it gradually decreases until the end of healing period. The optimum healing temperature is $28^{\circ} \mathrm{C}$ and $29^{\circ} \mathrm{C}$. Under these conditions, cell division is fast; the callus develops quickly and bridges the cut surfaces of scion and rootstock. Grafted seedlings can be in the dark for the first $24-48$ hours and light is then gradually increased; the target light intensity is 100 $\mu \mathrm{mol} /\left(\mathrm{m}^{2} \cdot \mathrm{s}\right)$ PPF (or 5400-7400 lux, depending on the light source).

The research on the processes taking place in the protected areas of the crops was oriented, especially to the analysis of the microclimate factors, their interaction and the influence of the constructive elements on them in greenhouses and solariums. As far as the microclimate conditions of the healing/acclimatization installations are concerned, their management was a priori considered that the same processes are being carried out here.

Even though the processes on the premises seem to be similar to those in greenhouses / solariums, these processes are different in healing rooms. The healing chambers are generally either small and very sophisticated premises, generally used in research, or large, especially used for industrial production of grafted seedlings.

The growth in demand for grafted seedlings makes that their traditionally producing in greenhouses and solaria to become an obsolete method at a given time. At the same time, this may lead to the development of interdisciplinary researches to analyze the dynamics of microclimate factors and other phenomena that occur in calming chambers, so that within them can be achieved optimal conditions of development and healing of grafted seedlings, irrespective of environmental conditions from outside.

\section{References}

1. C. Kubota, M. A. McClure, N. Kokalis-Burelle, M. G. Bausher, E. N. Rosskopf, HortScience, 43,1664-1669 (2008)

2. H. Hu, L. Xu, R. Wei, B. Zhu, Sensors, 11, 5792-5807 (2011)

3. C. Rivard, F. Louws, Sustainable Agriculture Research \& Education, 5, (2011)

4. S. J. Johnson, C. A. Miles, HortTechnology, 21, 752-758, (2011)

5. M. Ozores-Hampton, A.C. Frasca, Inst. Food Agr. Sci. Extension, HS1232, (2013)

6. J. Lee, M. Oda, Hortic. Reviews, 28, 61-124, (2010)

7. G. H. Germing, Wageningen University \& Research PhD theses, 104518, (1963)

8. C. Rivard, F. J. Louws, North Carolina State Extension Pub., 1-8, (2008)

9. C. A. Miles, P. Kreider, S. J. Johnson, J. Roozen, Washington State University Extension, 1-4, (2016)

10. B. Mun, Y. Jang, E. Goto, Y. Ishigami, C. Chun, Scientia Hortic., 130, 607-614, (2011)

11. F. Blestos, C. M. Olympios, Eur. J. Plant Sci. Biotechnol, 2, 62-73, (2008)

12. W. Dong, Z. Zhou, Y. Bu, J. Zhuo, L. Chen, and Y. Li, Arta Hortic. 1086, 51-57 (2015),

13. Y.-C. Chiu, L.-J. Jou, S. Chen, ASAE Annual International Meeting, 1-15, (1999)

14. Y.-C. Chiu, S. Chen, Y.-C. Chang, L.-J. Chou, IS ASAE, Int. Sem. on Agricultural Structure and Agricultural Engg., (2007)

15. X. Zhao and C. Kubota, "Vegetable Grafting International Field Trip Report-Part I: Taiwan and Japan," 1-17, (2015) 